Article

\title{
The Effects of Zr Doping on the Optical, Electrical and Microstructural Properties of Thin ZnO Films Deposited by Atomic Layer Deposition
}

\author{
Stephania Herodotou ${ }^{1, *}$, Robert E. Treharne ${ }^{2}$, Ken Durose ${ }^{2}$, Gordon J. Tatlock ${ }^{1}$ and \\ Richard J. Potter ${ }^{1}$ \\ Received: 16 September 2015 ; Accepted: 15 October 2015 ; Published: 27 October 2015 \\ Academic Editor: Peter J. King \\ 1 Centre for Materials and Structures, School of Engineering, University of Liverpool, Brownlow Hill, \\ Liverpool L69 3GH, UK; tatlock@liverpool.ac.uk (G.J.T.); rjpott@liverpool.ac.uk (R.J.P.) \\ 2 Stephenson Institute for Renewable Energy, University of Liverpool, Liverpool L69 7ZF, UK; \\ treharne@liverpool.ac.uk (R.E.T.); dph0kd@liverpool.ac.uk (K.D.) \\ * Correspondence: stephanieherodotou@gmail.com; Tel.: +44-151-794-5387; Fax: +44-151-794-4675
}

\begin{abstract}
Transparent conducting oxides (TCOs), with high optical transparency ( $\geqslant 85 \%)$ and low electrical resistivity $\left(10^{-4} \Omega \cdot \mathrm{cm}\right)$ are used in a wide variety of commercial devices. There is growing interest in replacing conventional TCOs such as indium tin oxide with lower cost, earth abundant materials. In the current study, we dope $\mathrm{Zr}$ into thin $\mathrm{ZnO}$ films grown by atomic layer deposition (ALD) to target properties of an efficient TCO. The effects of doping ( $0-10$ at. $\% \mathrm{Zr}$ ) were investigated for $\sim 100 \mathrm{~nm}$ thick films and the effect of thickness on the properties was investigated for 50-250 nm thick films. The addition of $\mathrm{Zr}^{4+}$ ions acting as electron donors showed reduced resistivity $\left(1.44 \times 10^{-3} \Omega \cdot \mathrm{cm}\right)$, increased carrier density $\left(3.81 \times 10^{20} \mathrm{~cm}^{-3}\right)$, and increased optical gap $(3.5 \mathrm{eV})$ with 4.8 at.\% doping. The increase of film thickness to $250 \mathrm{~nm}$ reduced the electron carrier/photon scattering leading to a further reduction of resistivity to $7.5 \times 10^{-4} \Omega \cdot \mathrm{cm}$ and an average optical transparency in the visible/near infrared (IR) range up to $91 \%$. The improved n-type properties of $\mathrm{ZnO}: \mathrm{Zr}$ films are promising for TCO applications after reaching the targets for high carrier density $\left(>10^{20} \mathrm{~cm}^{-3}\right)$, low resistivity in the order of $10^{-4} \Omega \cdot \mathrm{cm}$ and high optical transparency $(\geqslant 85 \%)$.
\end{abstract}

Keywords: $\mathrm{ZnO}$; $\mathrm{Zr}$ doped $\mathrm{ZnO}$; ALD; TCO; optical gap blue-shift

\section{Introduction}

Doped zinc oxide is of interest as a transparent conductive oxide (TCO), due to its low resistivity $\left(\leqslant 10^{-3} \Omega \cdot \mathrm{cm}\right)$, high transparency $(>80 \%)$ and wide bandgap (3.37 eV [1]). The abundance, and hence low cost of the major constituents, makes this an attractive alternative to indium tin oxide (ITO), which contains relatively scarce and expensive indium. TCOs must have low resistivity $\left(\leqslant 10^{-3} \Omega \cdot \mathrm{cm}[2]\right)$, high transparency $(>80 \%$ in the visible range $[3,4])$ and high carrier concentration $\left(\geqslant 10^{20} \mathrm{~cm}^{-3}[5]\right)$. ZnO tends to be intrinsically n-type and can be readily doped to degeneracy, hence providing high conductivity. The high carrier density resulting from the degenerate doping could also induce optical gap increases due to band filling effects (i.e., Burstein-Moss effect), which enhances transparency in the short wavelength region. The dopants used in $\mathrm{ZnO}$ should be shallow donors that provide extra ionized electrons. Dopants such as B [6,7], In [8,9], Co [10], Zr [11,12], Ge [13], Hf [14], Sn [15] have been studied, while the most common dopants are Al [16,17] and Ga [3,18-20]. The reported electrical and optical properties for doped $\mathrm{ZnO}$ are being improved 
by using different dopants in order to compete with ITO, which has a resistivity in the order of $10^{-4} \Omega \cdot \mathrm{cm}$ and transparency $\geqslant 85 \%[21]$.

Zirconium was chosen as the dopant in the current work due to its abundance, comparable ionic size to $\mathrm{Zn}$ and because it can potentially act as double donor providing up to two extra free electrons per ion when substituted for $\mathrm{Zn}^{2+}$ [22]. The close match between the ionic size of $\mathrm{Zr}^{4+}$ compared to $\mathrm{Zn}^{2+}$ [23] (i.e., $0.745 \AA$ for $\mathrm{Zr}$ and $0.740 \AA$ for $\mathrm{Zn}$ [22]) should help to minimize lattice distortion, which is often observed with other dopants such as $\mathrm{Al}$ [15]. Al can sit in interstitial positions in $\mathrm{ZnO}$ due to its small ionic radius [24], which can have the side effect of reducing interstitial Zn defects that act as native donors. This is avoided if the dopant ions are comparable in size to $\mathrm{Zn}$ ions as the dopant can readily sit on $\mathrm{Zn}$ sites, which is the case with $\mathrm{Zr}^{4+}$. An additional advantage of using $\mathrm{Zr}$ as a dopant is that it does not readily bond with $\mathrm{Zn}$ atoms, hence is unlikely to form secondary intermetallic phases [25]. A number of publications report on $\mathrm{Zr}$ doped $\mathrm{ZnO}$ deposited by spray pyrolysis [12,26], low temperature co-precipitation method [27], sol-gel [15,28-30], direct current (DC) magnetron sputtering [31-33], pulsed laser deposition (PLD) [34], and ALD [11].

ALD was used in the current study to produce modulated (delta) doped $\mathrm{ZnO}$ during the deposition itself, which is considered an advantageous method for accurate control of the carrier concentration. The self-limiting nature of ALD also provides excellent control over film thickness, good uniformity and conformality, while the relatively low growth temperature permits the use of temperature sensitive substrates such as polymers. A comprehensive report is presented in this paper about the limits in electrical properties of $\mathrm{Zr}$ doping in $\mathrm{ZnO}$ thin films, and how this affects the optical properties. Lin et al. [11] reported a study on $\mathrm{Zr}$ doped $\mathrm{ZnO}$ films deposited by ALD, covering topics such as the conductivity improvement and bandgap increase after doping, while focusing on the effect of annealing the doped samples. The current study builds up on this study by exploring how the $\mathrm{Zr}$ doping incorporated in the lattice, identifies possible causes of the carrier density decrease at high doping, investigates the doping effect on the grain growth, and finally examines the reason for the optical gap increase after doping.

\section{Experimental Section}

The deposition was carried out in an Oxford Instruments OpAL ALD reactor (Oxford Instruments, Bristol, UK) at $200^{\circ} \mathrm{C}$ using diethylzinc (DEZ) and tetrakis-ethylmethylamino zirconium (TEMAZ) as $\mathrm{Zn}$ and $\mathrm{Zr}$ sources respectively (supplied by SAFC Hitech), with water vapour as a co-reactant. Each precursor was delivered via vapour draw, with $\mathrm{DEZ}$ and $\mathrm{H}_{2} \mathrm{O}$ sources held at room temperature, while the TEMAZ was heated at $95{ }^{\circ} \mathrm{C}$. Films were deposited on sodalime glass microscope slides (cleaned with isopropanol and dried with nitrogen), and on virgin test grade $\mathrm{Si}$ (100) wafers. The growth rates of $\mathrm{ZnO}$ and $\mathrm{ZrO}_{2}$ individually at $200{ }^{\circ} \mathrm{C}$ were 1.87 and $0.65 \AA$ /cycle respectively. $\mathrm{Zr}$ doped $\mathrm{ZnO}$ with target doping ratios between 0 and $\sim 10$ at. $\%$ were deposited using an ALD delta doping methodology similar to the one reported by Chalker et al. [13]. As illustrated in Figure 1, ZnO multilayers were deposited by repeated ALD cycles, interspersed by one ALD cycle of $\mathrm{ZrO}_{2}$. The doping percentage was calculated from the number of doping cycles and the number of $\mathrm{Zr}$ atoms per $\mathrm{ZrO}_{2}$ monolayer. The film compositions presented in this study are nominal. The overall thickness of the layer was then controlled by repeating this "master" cycle multiple times. To improve the quality of the films, an ultra-thin $(\sim 2 \mathrm{~nm})$ buffer layer of $\mathrm{Al}_{2} \mathrm{O}_{3}$ was deposited on the substrates by ALD (using 20 cycles of trimethyl-aluminum and water) prior to the deposition of the doped $\mathrm{ZnO}$. The $\mathrm{Al}_{2} \mathrm{O}_{3}$ process promotes uniform deposition of the target films (probably due to self-cleaning), and is also believed to enhance the optical performance, since it provides transverse optical confinement with minimum absorption loss due to its wide energy gap [35].

Films grown on glass were used for all subsequent optical analysis, while films on $\mathrm{Si}(100)$ were used for microstructural analysis. Film thickness was assessed using a Rudolph Research Auto-EL-IV Ellipsometer (Rudolph Research Analytical, Hackettstown, NJ, USA) operating at $633 \mathrm{~nm}$. The microstructure was analysed by atomic force microscopy (AFM) (Bruker Corporation, Billerica, MA, 
USA) using a Bruker Multimode 8. The microstructure was calculated from the X-ray diffraction (XRD) patterns obtained using a Rigaku Miniflex Diffractometer (Rigaku Corporation, Tokyo, Japan) in the Bragg-Brentano geometry and using a $\mathrm{Cu} \mathrm{K} \alpha$ X-ray source. The chemical state of the films was determined by X-ray photoelectron spectroscopy (XPS) using a FISONS VG Escalab MKII Scientific $\mathrm{XPS}$ (Fisons plc, Ipswich, UK), with $\mathrm{Al} \mathrm{K \alpha}$ radiation. The electrical properties of the films were assessed by four-point-probe (4PP) and by Hall effect measurements. The 4PP measurements were carried out using a homebuilt system comprising of a Lucas Signatone Corp SP4 Probe head (Lucas Signatone Corp., Gilroy, CA, USA) and a Keithley 2400 series sourcemeter (Keithley Instruments Inc., Solon, $\mathrm{OH}, \mathrm{USA}$ ), while the Hall measurements used the same sourcemeter attached to a BioRad Hall probe station with a $0.3 \mathrm{~T}$ fixed magnet. Hall measurements were carried out using van-der-Pauw sample configuration with indium contacts. The optical properties of the films were assessed by UV-Vis transmission using a Shimadzu SolidSpec-3700DUV dual beam UV-Vis spectrophotometer (Shimadzu Corp., Kyoto, Japan) and by photoluminescence (PL) using a Horiba JY LabRam HR HR800 confocal Raman microscope (Horiba Ltd., Kyoto, Japan) fitted with a He-Cd UV laser (325 nm).

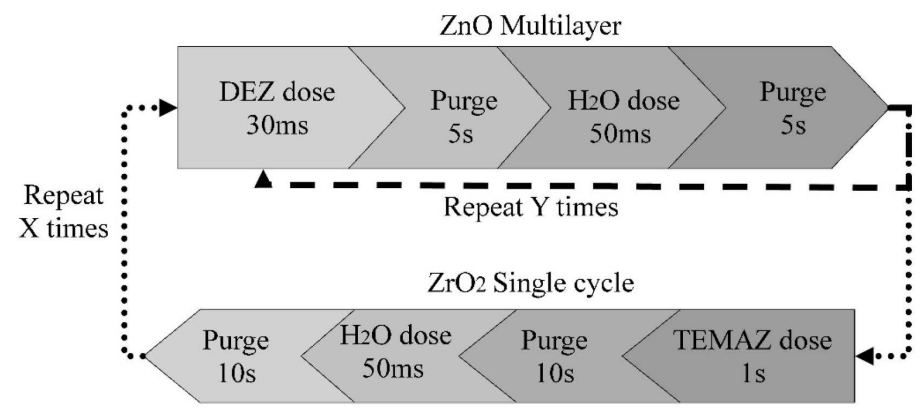

Figure 1. Schematic of the atomic layer deposition (ALD) process used to deposit Zr doped ZnO.

\section{Results and Discussion}

\subsection{Effect of Doping and Film Thickness on the Microstructure and Electrical Properties.}

Figure 2 shows the effect of doping on the resistivity, carrier density and mobility as a function of $\mathrm{Zr}$ doping for films that are $\sim 85 \mathrm{~nm}$ thick. The carrier density increases from $1.0 \times 10^{20}$ to $3.81 \times 10^{20} \mathrm{~cm}^{-3}$ as the doping is increased from zero to 4.8 at.\%, leading to a decrease in resistivity from $3.02 \times 10^{-3}$ to $1.44 \times 10^{-3} \Omega \cdot \mathrm{cm}$.

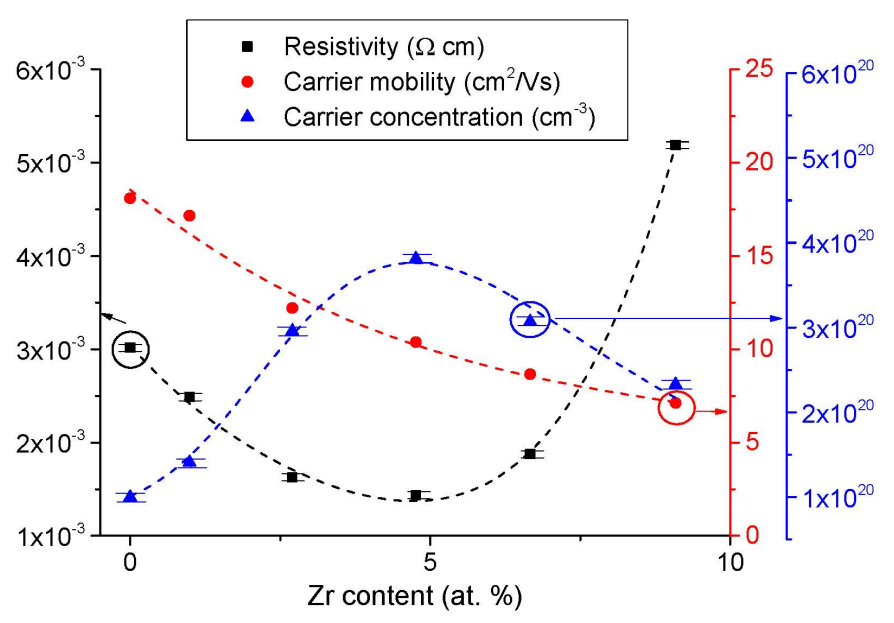

Figure 2. $\mathrm{Zr}$ doping dependence of resistivity, carrier concentration and mobility for $\mathrm{ZnO}$ films $\sim 85 \mathrm{~nm}$ thick. 
The increase in carrier concentration is mostly attributed to the ionisation of the $\mathrm{Zr}$ atoms on $\mathrm{Zn}$-sites, where the $\mathrm{Zr}^{4+}$ ions replace $\mathrm{Zn}^{2+}$ ions, thus donating two extra electrons to the system [28]. This interpretation is supported by previously reported theoretical studies that suggest that $Z r$ dopant prefers $\mathrm{Zn}$-site substitution $\left(\mathrm{Zr}_{\mathrm{Zn}}\right)$ in the bulk of the film rather than locating at the surface as is the case of $\mathrm{Cu}$ and $\mathrm{Ag}$ [36]. First principles calculations have also shown that $\mathrm{Zr}_{\mathrm{Zn}}$ has lower formation energy than interstitial $\left(\mathrm{Zr}_{\mathrm{i}}\right)$ and oxygen vacancy $\left(\mathrm{Zr}_{\mathrm{O}}\right)$ positions [23]. In the current study, XPS reveals evidence that $\mathrm{Zr}$ is substitutional to $\mathrm{Zn}$ sites $\left(\mathrm{Zr}_{\mathrm{Zn}}\right)$, which indicates that $\mathrm{Zr}$ is in its ionic state $\left(\mathrm{Zr}^{4+}\right)$ in the $\mathrm{Zr}-\mathrm{O}$ structure. The binding energies of $\mathrm{Zr} 3 \mathrm{~d}_{5 / 2}$ and $\mathrm{Zr} 3 \mathrm{~d}_{3 / 2}$ are 182.4 and $184.7 \mathrm{eV}$ respectively (Figure 3a) [37]. In addition, XRD provides evidence that $\mathrm{Zr}$ is not forming interstitial defects as an increase in the crystal alignment is observed at high doping levels (Figure 3b), suggesting that the hexagonal structure is maintained after doping. Interstitial $\mathrm{Zr}$ is expected to promote amorphization [12]. The XRD also indicates that very little lattice distortion is induced by Zr doping. A nominal lattice constant increase of $\sim 0.01 \AA$ with 4.8 at. \% doping (i.e., $\mathrm{d}_{(10 \overline{1} 0)}=2.806 \AA$ for 0 at. $\%$ and $\mathrm{d}_{(10 \overline{1})}=2.814 \AA$ for 4.8 at. $\%, \mathrm{~d}_{(0002)}=2.600 \AA$ for both) suggests that $\mathrm{Zr}$ is not sitting on oxygen vacancy sites within the lattice as this would have created larger lattice distortion due to the large repulsive forces between $\mathrm{Zr}$ and $\mathrm{Zn}$ atoms [23].

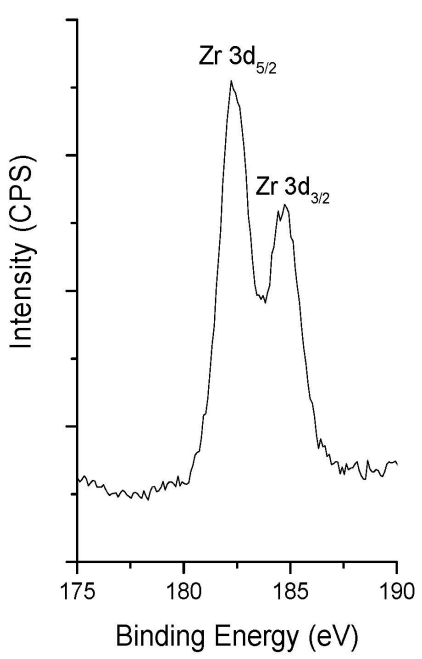

(a)

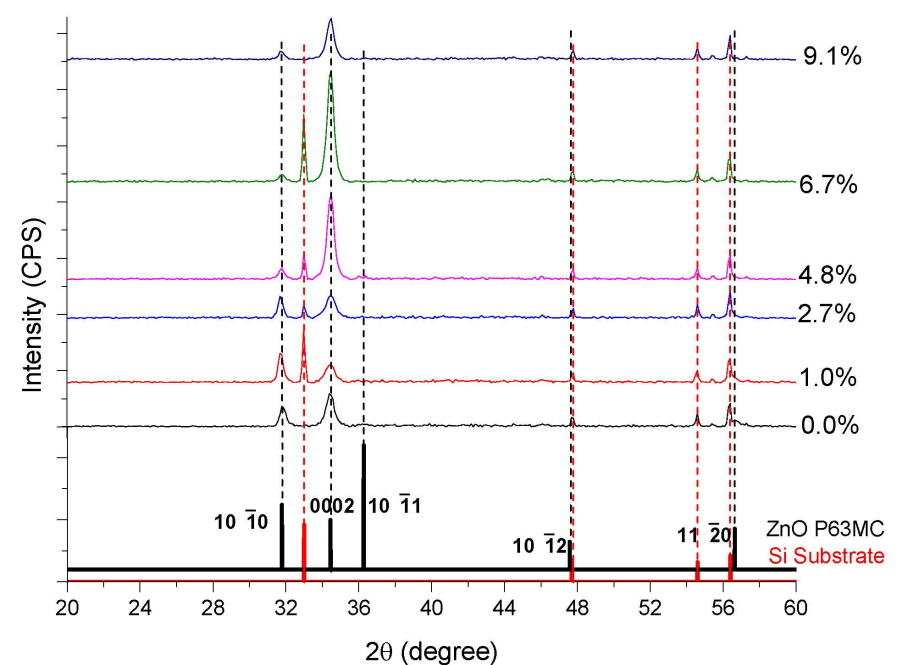

(b)

Figure 3. (a) X-ray photoelectron spectroscopy (XPS) spectrum for the Zr 3d peaks for $250 \mathrm{~nm}$ thick film with 4.8 at. $\%$ Zr doping; (b) X-ray diffraction (XRD) patterns of Zr doped ZnO films.

The ionic bonding between $\mathrm{Zn}^{2+}$ and $\mathrm{O}^{2-}$ suggests that the free electrons causing the n-type semiconductor behavior in the doped $\mathrm{ZnO}$ originate from the intrinsic donors (zinc interstitials and oxygen vacancies), hydrogen acting as donor [38] and the donor dopants $\left(\mathrm{Zr}^{4+}\right)$. The hydrogen concentration is not expected to change significantly as $\mathrm{Zr}$ is added and hence is not expected to contribute significantly to the increase in carrier density due to doping. The main increase in carrier density with doping is attributed to $\mathrm{Zr}^{4+}$ acting as an electron donor, potentially providing up to two extra carriers per ion. If each $\mathrm{Zr}^{4+}$ dopant ion were acting as a double donor, then the addition of 4.8 at.\% $\mathrm{Zr}$ to the $\mathrm{ZnO}$ would theoretically lead to an increase of $\sim 4.1 \times 10^{21} \mathrm{~cm}^{-3}$ in the carrier density. In reality, Hall effect measurements indicate that the addition of 4.8 at. $\% \mathrm{Zr}$ causes the carrier density to rise by only $\sim 2.8 \times 10^{20} \mathrm{~cm}^{-3}$, which possibly suggests the formation of neutral defects during doping and segregation of $\mathrm{Zr}$ at grain boundaries.

As the doping level increases beyond 4.8 at.\%, the carrier concentration begins to decrease again, resulting in an increase of resistivity. Previous studies [28,37] have attributed this high level doping behavior to the formation of segregated $\mathrm{ZrO}_{2}$, which inhibits effective doping of the $\mathrm{ZnO}$ and 
hence leads to a reduction in carrier concentration. The $\mathrm{ZrO}_{2}$ tends to cluster at grain boundaries, and this has been shown to result in suppression of grain growth and hence smaller grains [15,37]. AFM studies have been carried out on samples spanning the doping range investigated and provide evidence that grain size decreases as the doping level increases. Figure 4 shows examples of AFM for undoped and 4.8 at.\% doped films ( $250 \mathrm{~nm}$ thick) and clearly shows that the films are made-up of needle-like grains. Although it is not possible to analyze grain length using AFM due to the unknown orientation of individual grains, it is possible to study grain widths. Numerical analysis reveals that average grain width reduces from $32 \mathrm{~nm}$ for the undoped sample, to $25 \mathrm{~nm}$ for the 4.8 at.\% sample suggesting that doping is indeed suppressing the grain size. This trend of grain width reduction continues as the doping level is increased. The same effect is observed for the thinner $(\sim 85 \mathrm{~nm})$ films, where the average grain width reduces from $25 \mathrm{~nm}$ for the undoped film to $20 \mathrm{~nm}$ for the 4.8 at.\% film and $18 \mathrm{~nm}$ for the 9.1 at.\% film (data not shown).
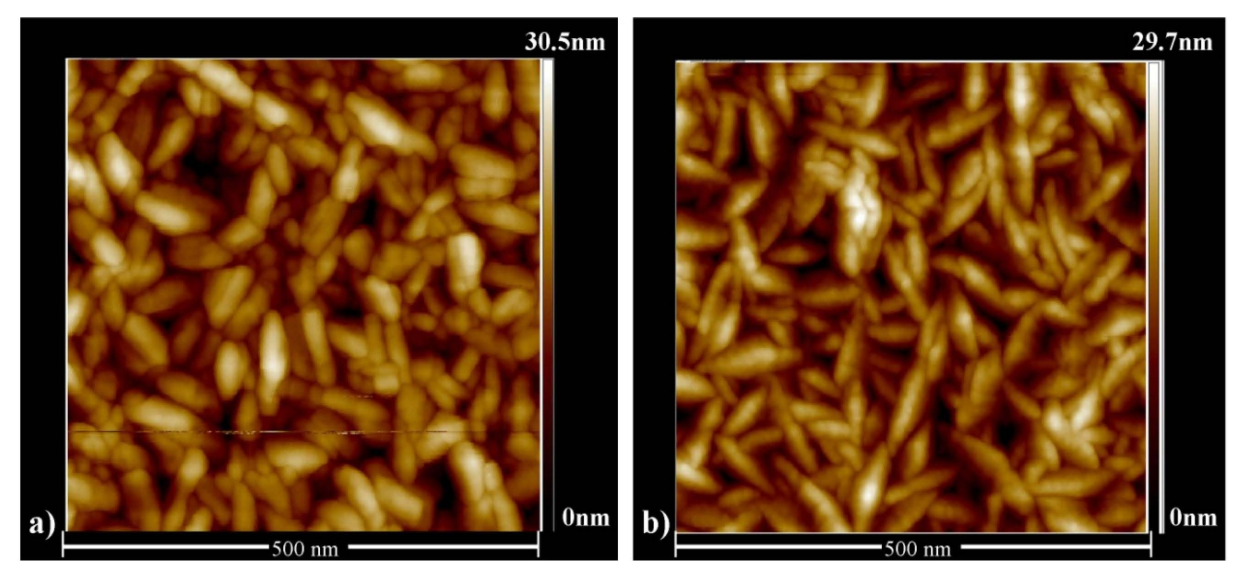

Figure 4. Atomic force microscopy (AFM) of (a) Un-doped; (b) 4.8 at.\% doped ZnO films with a nominal thickness of $\sim 250 \mathrm{~nm}$.

In addition to dopant segregation having a direct effect on the effectiveness of the doping, the suppressed grain size due to the doping is believed to have a secondary effect on the carrier density by reducing zinc vacancies $\left(\mathrm{V}_{\mathrm{Zn}}\right)$. The PL data (Figure 5) showed increased $\mathrm{V}_{\mathrm{Zn}}$ concentration for the heavier doped films. The PL shows two main emission features for the doped films attributed to the recombination of carries from the conduction band minimum (CBM) to the $\mathrm{V}_{\mathrm{Zn}}{ }^{0}$ state (3.14-3.15 eV) [39] and the increased band-to-band recombination energy due to Burstein-Moss effect $(\sim 3.5 \mathrm{eV})$. The CBM to $\mathrm{V}_{\mathrm{Zn}}{ }^{0}$ emission feature is the shoulder on the high energy side of the main peak and is related to the zinc vacancy concentration in the films. The integrated area of this PL feature was found by a nonlinear curve fitting (Loranzian) using two peaks for all films and the data are shown in the inset graph. The intensity of the high energy peak was zero for the two lower doped films (0-1 at.\%) and thus is not shown in the graph. The integrated area of the CBM to $\mathrm{V}_{\mathrm{Zn}}{ }^{0}$ emission shows a slight reduction as the doping level increases from 3 to 5 at. $\%$ followed by an increase as the doping level increases up to 9.1 at.\%. Zinc vacancies act as intrinsic acceptors and are easily formed in n-type materials by means of their formation energy decrease as the Fermi level increases [40]. Grain boundaries act as efficient sinks for zinc vacancies [41], hence, the concentration of $\mathrm{V}_{\mathrm{Zn}}$ is proportional to the grain boundary areas. The grain boundary areas increase at high doping level would be expected to correlate to an increase of the density of zinc vacancies per unit volume. The combination of $\mathrm{V}_{\mathrm{Zn}}$ and $\mathrm{Zr}^{4+}$ segregated at the boundaries is likely to lead to the formation of neutral defects and hence to the reduction of free electrons. The increase of the defect concentration observed in the PL data is consistent with the carrier density reduction for the heavier doped films. 


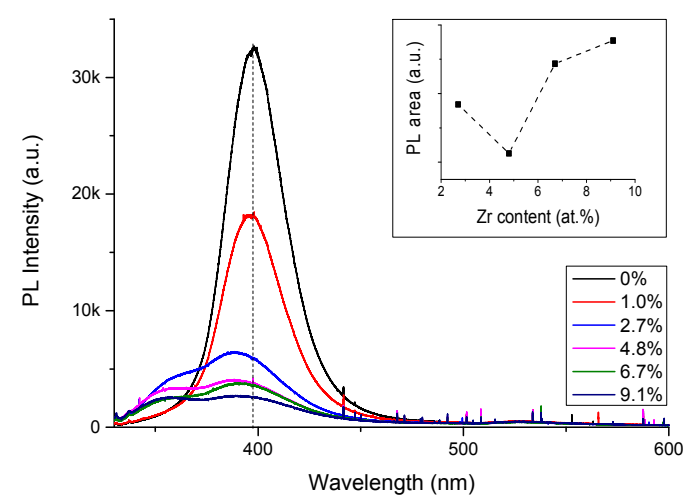

Figure 5. Zr doping dependence of photoluminescence (PL) emission for films $\sim 85 \mathrm{~nm}$ thick grown on glass substrates. The inset graph shows the integrated area of the conduction band minimum (CBM) to the $\mathrm{V}_{\mathrm{Zn}}{ }^{0}$ emission feature as a function of doping level (the feature is the shoulder on the high energy side of the main peak found by nonlinear curve fitting).

The carrier mobility (Figure 2) decreases as the doping level increases, and this could be due to ionised impurity and possibly grain boundary scattering caused by the grain size reduction. The effect of doping concentration on resistivity (initial decrease followed by an increase), is widely reported for other doped $\mathrm{ZnO}$ systems, such as $\mathrm{ZnO}: \mathrm{Al}$ [16], $\mathrm{ZnO}: \mathrm{Ge}$ [13], ZnO:Ga [20] and $\mathrm{ZnO}: \mathrm{Ni}$ [42]. Having established the $\mathrm{Zr}$ doping level that provides the lowest resistivity, the doping level was fixed at 4.8 at.\% and the effects of film thickness were investigated. Figure 6a shows the effect of film thickness on the resistivity, carrier concentration and carrier mobility for the doped films. The mobility increases with film thickness up to a maximum value of $19.7 \mathrm{~cm}^{2} / \mathrm{Vs}$ It may be postulated that this behavior is consistent with an interface carrier scattering mechanism, with a higher value observed (for the thicker film) being consistent with that of the bulk material. The carrier density reaches $4.6 \times 10^{20} \mathrm{~cm}^{-3}$, and it is largely independent of film thickness (for films $>80 \mathrm{~nm}$ thick) as expected. The drop-off effect for very thin films $(<100 \mathrm{~nm})$ is attributed to the strain sensitivity of very thin films before reaching the bulk thickness.

The tensile strain measured from (1010) XRD peak positions (Figure $6 \mathrm{~b}$ ) appears to have the same increasing trend as the carrier density. Strain effects induced by the thickness changes (larger grains) could contribute to shifts in the distribution of the density of states and cause a small reduction in the bandgap [43]. In the current films the gap is expected to be reduced as the tensile strain increases with thickness, causing an increase of the carrier density.

The combination of increasing mobility and carrier density results in an asymptotic decrease in resistivity by a factor of 3 as thickness increases from 50 to $250 \mathrm{~nm}$ (Figure 6a). This is consistent with previous studies of thickness effect using other dopants such as $\mathrm{Ga}$ [18] and $\mathrm{Cu}$ [44].

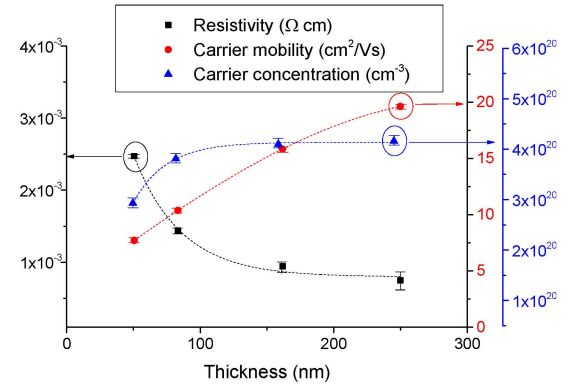

(a)

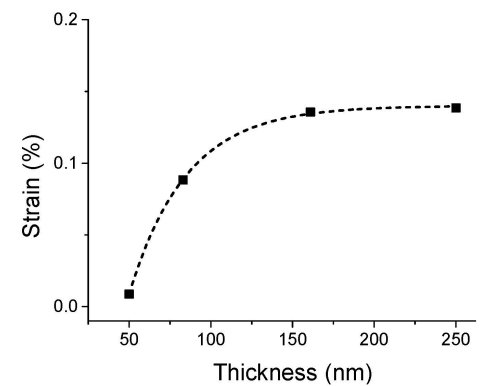

(b)

Figure 6. (a) Thickness dependence of resistivity, carrier concentration and mobility for ZnO films doped with 4.8 at.\% Zr; (b) Thickness dependence of strain in (1010) plane for ZnO films doped with 4.8 at. $\%$ Zr. 
The lowest resistivity value achieved in this work was $7.5 \times 10^{-4} \Omega \cdot \mathrm{cm}$ for a $250 \mathrm{~nm}$ film, with resistivity remaining below $10^{-3} \Omega \cdot \mathrm{cm}$ for films $>150 \mathrm{~nm}$. This is in the desired range for TCO applications. This value is lower than other published values for $\mathrm{Zr}$ doped $\mathrm{ZnO}$ films fabricated by magnetron sputtering for which the resistivity of films $200-300 \mathrm{~nm}$ thick was $\sim 2 \times 10^{-3} \Omega \cdot \mathrm{cm}[31,37]$, and it is also below the value of vacuum annealed $450 \mathrm{~nm}$ thick film which achieved $9.8 \times 10^{-4} \Omega \cdot \mathrm{cm}$ [33]. It is also comparable to the lowest resistivity values published for other doped $\mathrm{ZnO}$ coatings grown by ALD such as $\mathrm{Al}$ doped $\left(7.7 \times 10^{-4} \Omega \cdot \mathrm{cm}\right)$ [17] and Ga doped films $\left(8 \times 10^{-4} \Omega \cdot \mathrm{cm}\right)[20]$.

\subsection{Effect of Doping on the Optical Properties.}

Figure 7 shows the raw optical transmission spectra (i.e., before normalisation) of $\sim 85 \mathrm{~nm}$ doped $\mathrm{ZnO}$ films with various fractions of $\mathrm{Zr}$. Films with 1 to 4.8 at.\% $\mathrm{Zr}$ have a high normalised transparency, averaging $87 \%-88 \%$ in the visible (380-780 nm) and $89 \%$ in the near IR (780-1400 nm) range (normalisation was done by scaling the transmission values by the coefficient necessary to increase the experimental value for uncoated glass to $100 \%$ ). The normalized transparency in the visible spectrum was at its maximum (91\%) for a thickness of $161 \mathrm{~nm}$, and in the near IR region reached $91 \%$ with a thinner film $(50 \mathrm{~nm})$. The high transparency and low resistivity results in high values of the figure of merit calculated by the formula derived by Haacke [45] as expressed in Equation (1).

$$
F_{T C}=\frac{T^{10}}{R_{s}}
$$

where $T$ is the average transmittance in the visible region and $R_{S}$ is the sheet resistance. The value for the thicker doped film $(250 \mathrm{~nm})$ was $0.93 \times 10^{-2} \Omega^{-1}$ while for a thinner one (83 nm) was at $0.14 \times 10^{-2} \Omega^{-1}$. For comparison ITO typically has $1.19 \times 10^{-2} \Omega^{-1}$ [46]. The results of the current study are also promising compared to other doped $\mathrm{ZnO}$ films deposited by ALD, such as $100 \mathrm{~nm}$ Al-doped $\mathrm{ZnO}\left(F_{T C}=0.10 \times 10^{-2} \Omega^{-1}\right)$ [47], $180 \mathrm{~nm}$ In-doped $\mathrm{ZnO}$ $\left(F_{T C}=0.12 \times 10^{-2} \Omega^{-1}\right)[48], 100 \mathrm{~nm}$ Ti-doped $\mathrm{ZnO}\left(F_{T C}=0.12 \times 10^{-2} \Omega^{-1}\right)$ [49] and $200 \mathrm{~nm}$ Hf-doped $\mathrm{ZnO}\left(F_{T C}=0.36 \times 10^{-2} \Omega^{-1}\right)[14]$.

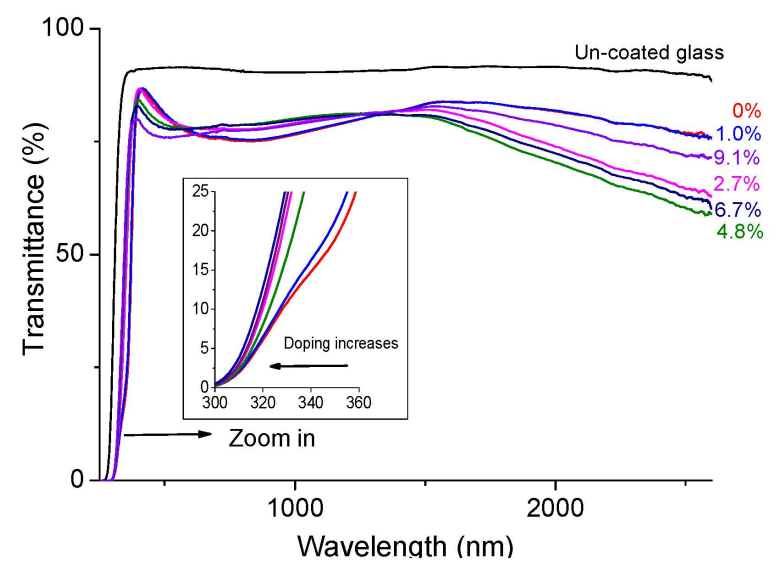

Figure 7. Transmission spectra of $\sim 100 \mathrm{~nm}$ thick $\mathrm{Zr}$ doped $\mathrm{ZnO}$ films as a function of the atomic concentration of $\mathrm{Zr}$.

As expected, the long wavelength plasma edge of the transmission spectra is affected by doping as the plasma frequency is proportional to the square root of the carrier concentration. The optical gap was measured experimentally by both optical transmission and by PL. In transmission the values for undoped and 4.8 at.\% doped samples were 3.27 and $3.53 \mathrm{eV}(\Delta E=0.26 \mathrm{eV})$ which are in close agreement with PL values of 3.21 and $3.52 \mathrm{eV}(\Delta E=0.31 \mathrm{eV})$. The slight differences are comparable 
with the expected difference between absorption and emission processes. Figure 8 shows a direct relationship between the blue shift in the optical gap and carrier concentration (controlled by doping). The PL shift represents the band-to-band recombination energy shift and the spectrophotometer shift represents the gap estimated using Tauc plots.

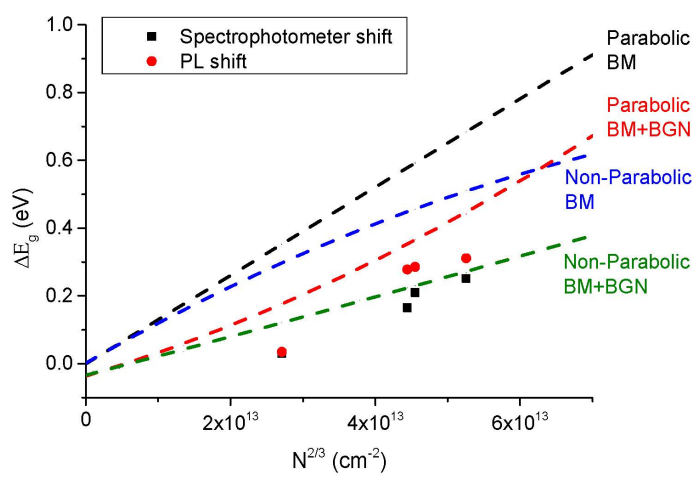

Figure 8. Optical gap difference between the doped and un-doped films as a function of carrier concentration.

The blue shift of the optical gap for low doping levels can be explained by a combination of Burstein-Moss (BM) [50] effect due to degenerate band filling of the conduction band (i.e., when $n>3.7 \times 10^{19} \mathrm{~cm}^{-3}$ [51]) and bandgap renormalisation (i.e., narrowing) due to many body effects from the increased carrier concentration. To confirm those effects, mathematical models were applied to calculate the effective masses of parabolic (i.e., $m^{*}=0.28 m_{0}$ [4]) and non-parabolic conductions bands [52] and to estimate the shifts due to BM [53] and bandgap narrowing (BGN) [54] as expressed in Equations (2) and (3) respectively (Figure 8).

$$
\begin{aligned}
E_{B M} & =\frac{\hbar^{2}}{2 m^{*}}\left(3 \pi^{2} n\right)^{2 / 3} \\
E_{B G N} & =\frac{e^{2}}{2 \pi \varepsilon_{0} \varepsilon_{r}}\left(\frac{3}{\pi} n\right)^{1 / 3}
\end{aligned}
$$

The experimental results agree reasonably well with the non-parabolic band model with both effects. The non-parabolic CB was due to the band deformation by the high number of free electrons. Hence, by modulated $\mathrm{Zr}$ doping the optical gap can be tuned in a predictable way.

\section{Conclusions}

ALD grown $\mathrm{ZnO}$ : $\mathrm{Zr}$ films showed that doping offers control over resistivity reduction up to 4.8 at.\% due to the extra ions offered by the substitution of $\mathrm{Zr}^{4+}$ to $\mathrm{Zn}^{2+}$. At heavier doping the carrier concentration was reduced due to $\mathrm{Zr}$ segregation to grain boundaries consistent with the suppression of grain growth, and the formation of neutral defects at the boundaries (increase of zinc vacancies). The resistivity was decreased as thickness increasing $\left(7.5 \times 10^{-4} \Omega \cdot \mathrm{cm}\right)$ leading to scattering reduction. The remaining decrease was accompanied by a carrier density increase $\left(4.6 \times 10^{20} \mathrm{~cm}^{-3}\right)$ influenced by the tensile strain. The optical gap of the degenerate films could be enlarged up to $3.5 \mathrm{eV}$ due to the net effects of the Burstein-Moss shift and bandgap renormalisation. The transparency of the doped films was up to $91 \%$ in the visible and near IR regions. The properties resulted in a high figure of merit $\left(0.93 \times 10^{-2} \Omega^{-1}\right)$ that is close to figures of merit for ITO films $\left(1.19 \times 10^{-2} \Omega^{-1}\right.$ [46]) which is the material targeted to be replaced. This figure is higher than other doped $\mathrm{ZnO}$ films deposited by ALD, such as In-doped $\mathrm{ZnO}\left(0.12 \times 10^{-2} \Omega^{-1}\right)$ [48] and Hf-doped $\mathrm{ZnO}\left(0.36 \times 10^{-2} \Omega^{-1}\right)[14]$. As a result, the $\mathrm{Zr}$-doped $\mathrm{ZnO}$ films grown by ALD on sodalime glass 
can find applications as TCOs with properties that comply with the targets for high carrier density $\left(>10^{20} \mathrm{~cm}^{-3}\right)$, low resistivity in the order of $10^{-4} \Omega \cdot \mathrm{cm}$ and high optical transparency $(\geqslant 85 \%)$.

Acknowledgments: The PhD studentship for Stephania Herodotou was funded by EPSRC via the Doctoral Training Account. In addition, the work was partially supported by EPSRC grant EP/K005901/1.

Author Contributions: Stephania Herodotou and Richard J. Potter conceived and designed the experiments and jointly wrote the paper; Stephania Herodotou performed the experiments; all authors contributed to the analyzed and interpretation of the data and to editing the paper; Richard J. Potter supervised the research.

Conflicts of Interest: The authors declare no conflict of interest.

\section{References}

1. Klingshirn, C. ZnO: From basics towards applications. Phys. Status Solidi B 2007, 244, 3027-3073. [CrossRef]

2. Lewis, B.G.; Paine, D.C. Applications and processing of transparent conducting oxides. MRS Bull. 2000, 25, 22-27. [CrossRef]

3. Walsh, A.; Da Silva, J.L.F.; Wei, S. Multi-component transparent conducting oxides: Progress in materials modelling. J. Phys. Condens. Matter 2011, 23. [CrossRef] [PubMed]

4. Ellmer, K. Resistivity of polycrystalline zinc oxide films: Current status and physical limit. J. Phys. D Appl. Phys. 2001, 34, 3097-3108. [CrossRef]

5. Minami, T. Transparent conducting oxide semiconductors for transparent electrodes. Semicond. Sci. Technol. 2005, 20, S35-S44. [CrossRef]

6. Faÿ, S.; Steinhauser, J.; Nicolay, S.; Ballif, C. Polycrystalline ZnO:B grown by LPCVD as TCO for thin film silicon solar cells. Thin Solid Film. 2010, 518, 2961-2966. [CrossRef]

7. Faÿ, S.; Steinhauser, J.; Oliveira, N.; Vallat-Sauvain, E.; Ballif, C. Opto-electronic properties of rough LP-CVD ZnO:B for use as TCO in thin-film silicon solar cells. Thin Solid Film. 2007, 515, 8558-8561. [CrossRef]

8. Ilican, S.; Caglar, Y.; Caglar, M.; Demirci, B. Polycrystalline indium-doped ZnO thin films: Preparation and characterization. J. Optoelectron. Adv. Mater. 2008, 10, 2592-2598.

9. Huang, C.; Wang, M.; Deng, Z.; Cao, Y.; Liu, Q.; Huang, Z.; Huang, Q. Low content indium-doped zinc oxide films with tunable work function fabricated through magnetron sputtering. Semicond. Sci. Technol. 2010, 25. [CrossRef]

10. Wang, C.C.; Man, B.Y.; Liu, M.; Chen, C.S.; Jiang, S.Z.; Yang, S.Y.; Xu, S.C.; Gao, X.G.; Hu, B. The intrinsic room-temperature ferromagnetism in ZnO:Co thin films deposited by PLD. Adv. Condens. Matter Phys. 2012, 2012. [CrossRef]

11. Lin, M.; Chang, Y.; Chen, M.; Chu, C. Characteristics of Zr-doped ZnO thin films grown by atomic layer deposition. J. Electrochem. Soc. 2011, 158, D395-D399. [CrossRef]

12. Gokulakrishnan, V.; Parthiban, S.; Jeganathan, K.; Ramamurthi, K. Investigation on the effect of Zr doping in ZnO thin films by spray pyrolysis. Appl. Surf. Sci. 2011, 257, 9068-9072. [CrossRef]

13. Chalker, P.R.; Marshall, P.A.; King, P.J.; Dawson, K.; Romani, S.; Williams, P.A.; Rosseinsky, M.J. Atomic layer deposition of germanium-doped zinc oxide films with tunable ultraviolet emission. J. Mater. Chem. 2012, 22, 12824-12829. [CrossRef]

14. Ahn, C.H.; Kim, J.H.; Cho, H.K. Tunable electrical and optical properties in composition controlled Hf:ZnO thin films grown by atomic layer deposition. J. Electrochem. Soc. 2012, 159, H384-H387. [CrossRef]

15. Tsay, C.; Lee, W. Effect of dopants on the structural, optical and electrical properties of sol-gel derived ZnO semiconductor thin films. Curr. Appl. Phys. 2013, 13, 60-65. [CrossRef]

16. Lee, D.; Kim, H.; Kwon, J.; Choi, H.; Kim, S.; Kim, K. Structural and electrical properties of atomic layer deposited Al-doped ZnO films. Adv. Funct. Mater. 2011, 21, 448-455. [CrossRef]

17. Dasgupta, N.P.; Neubert, S.; Lee, W.; Trejo, O.; Lee, J.; Prinz, F.B. Atomic layer deposition of Al-doped ZnO films: Effect of grain orientation on conductivity. Chem. Mater. 2010, 22, 4769-4775. [CrossRef]

18. Chalker, P.R.; Marshall, P.A.; Romani, S.; Rosseinsky, M.J.; Rushworth, S.; Williams, P.A.; Ridealgh, J. Atomic layer deposition of gallium-doped zinc oxide transparent conducting oxide films. MRS Proc. 2012, 1315, 39-44. [CrossRef]

19. Chalker, P.R.; Marshall, P.A.; Romani, S.; Roberts, J.W.; Irvine, S.J.C.; Lamb, D.A.; Williams, P.A. Atomic layer deposition of Ga-doped $\mathrm{ZnO}$ transparent conducting oxide substrates for CdTe-based photovoltaics. J. Vac. Sci. Technol. 2013, 31. [CrossRef] 
20. Saito, K.; Hiratsuka, Y.; Omata, A.; Makino, H.; Kishimoto, S.; Yamamoto, T.; Hirayama, H. Atomic layer deposition and characterization of Ga-doped ZnO thin films. Superlattices Microstruct. 2007, 42, $172-175$. [CrossRef]

21. Guillén, C.; Herrero, J. TCO/metal/TCO structures for energy and flexible electronics. Thin Solid Film. 2011, 520, 1-17. [CrossRef]

22. Duan, X.M.; Stampfl, C.; Bilek, M.M.; McKenzie, D.R.; Wei, S. Design of shallow acceptors in ZnO through early transition metals codoped with $\mathrm{N}$ acceptors. Phys. Rev. B 2011, 83. [CrossRef]

23. Wang, F.; Lv, M.; Pang, Z.; Yang, T.; Dai, Y.; Han, S. Theoretical study of structural, optical and electrical properties of zirconium-doped zinc oxide. Appl. Surf. Sci. 2008, 254, 6983-6986. [CrossRef]

24. Gabás, M.; Landa-Cánovas, A.; Luis Costa-Krämer, J.; Agulló-Rueda, F.; González-Elipe, A.R.; Díaz-Carrasco, P.; Ramón Ramos-Barrado, J. Differences in n-type doping efficiency between Al- and Ga-ZnO films. J. Appl. Phys. 2013, 113. [CrossRef]

25. Subash, B.; Krishnakumar, B.; Swaminathan, M.; Shanthi, M. Highly efficient, solar active, and reusable photocatalyst: Zr-loaded Ag-ZnO for reactive red 120 dye degradation with synergistic effect and dye-sensitized mechanism. Langmuir 2013, 29, 939-949. [CrossRef] [PubMed]

26. Bahedi, K.; Addou, M.; Jouad, M.E.; Bayoud, S.; Sofiani, Z. Effects of deposition temperature on the surface roughness and the nonlinear optical susceptibility of sprayed deposited ZnO:Zr thin films. Appl. Surf. Sci. 2009, 255, 9054-9057. [CrossRef]

27. Selvam, N.C.S.; Vijaya, J.J.; Kennedy, L.J. Effects of morphology and Zr doping on structural, optical, and photocatalytic properties of ZnO nanostructures. Ind. Eng. Chem. Res. 2012, 51, 16333-16345. [CrossRef]

28. Paul, G.K.; Bandyopadhyay, S.; Sen, S.K.; Sen, S. Structural, optical and electrical studies on sol-gel deposited Zr doped ZnO films. Mater. Chem. Phys. 2003, 79, 71-75. [CrossRef]

29. Zhang, J.; Gao, D.; Yang, G.; Zhang, J.; Shi, Z.; Zhang, Z.; Xue, D. Synthesis and magnetic properties of Zr doped ZnO nanoparticles. Nanoscale Res. Lett. 2011, 6, 1-21. [CrossRef] [PubMed]

30. Tsay, C.; Fan, K. Optimization of Zr-doped ZnO thin films prepared by sol-gel method. Mater. Trans. 2008, 49, 1900-1904. [CrossRef]

31. Zhang, H.; Lei, C.; Liu, H.; Yuan, C. Low-temperature deposition of transparent conducting ZnO:Zr films on PET substrates by DC magnetron sputtering. Appl. Surf. Sci. 2009, 255, 6054-6056. [CrossRef]

32. Yadav, S.K.; Vyas, S.; Chandra, R.; Chaudhary, G.P.; Nath, S.K. Study of electrical and optical properties of $\mathrm{Zr}$-doped $\mathrm{ZnO}$ thin films prepared by dc reactive magnetron sputtering. Adv. Mater. Res. 2009, 67, 161-166. [CrossRef]

33. Zhang, H.; Liu, H.; Feng, L. Influence of annealing temperature on the properties of ZnO:Zr films deposited by direct current magnetron sputtering. Vacuum 2010, 84, 833-836. [CrossRef]

34. Kim, H.; Horwitz, J.S.; Kim, W.H.; Qadri, S.B.; Kafafi, Z.H. Anode material based on Zr-doped ZnO thin films for organic light-emitting diodes. Appl. Phys. Lett. 2003, 83, 3809-3811. [CrossRef]

35. Yu, S.F.; Yuen, C.; Lau, S.P.; Wang, Y.G.; Lee, H.W.; Tay, B.K. Ultraviolet amplified spontaneous emission from zinc oxide ridge waveguides on silicon substrate. Appl. Phys. Lett. 2003, 83, 4288-4290. [CrossRef]

36. Pala, R.G.S.; Metiu, H. Modification of the oxidative power of $\mathrm{ZnO}$ (1010) surface by substituting some surface Zn atoms with other metals. J. Phys. Chem. C 2007, 111, 8617-8622. [CrossRef]

37. Lv, M.; Xiu, X.; Pang, Z.; Dai, Y.; Ye, L.; Cheng, C.; Han, S. Structural, electrical and optical properties of zirconium-doped zinc oxide films prepared by radio frequency magnetron sputtering. Thin Solid Film. 2008, 516, 2017-2021. [CrossRef]

38. Van de Walle, C.G.; Neugebauer, J. Universal alignment of hydrogen levels in semiconductors, insulators and solutions. Lett. Nat. 2003, 423, 626-628. [CrossRef] [PubMed]

39. Chaaya, A.A.; Viter, R.; Bechelany, M.; Alute, Z.; Erts, D.; Zalesskaya, A.; Miele, P. Evolution of microstructure and related optical properties of $\mathrm{ZnO}$ grown by atomic layer deposition. Beilstein J. Nanotechnol. 2013, 4, 690-698. [CrossRef] [PubMed]

40. Janotti, A.; Van De Walle, C.G. Fundamentals of zinc oxide as a semiconductor. Rep. Prog. Phys. $2009,72$. [CrossRef]

41. Priester, L. Grain Boundaries: From Theory to Engineering; Springer Science \& Business Media: Medford, MA, USA, 2012; pp. 135-137.

42. Kim, K.; Kim, G.; Woo, J.; Kim, C. Characteristics of nickel-doped zinc oxide thin films prepared by sol-gel method. Surf. Coat. Technol. 2008, 202, 5650-5653. [CrossRef] 
43. Pankove, J.I. Optical Processes in Semiconductors; Courier Corporation: North Chelmsford, MA, USA, 1971.

44. Rossnagel, S.M.; Kuan, T.S. Alteration of $\mathrm{Cu}$ conductivity in the size effect regime. J. Vac. Sci. Technol. B 2004, 22, 240-247. [CrossRef]

45. Haacke, G. New figure of merit for transparent conductors. J. Appl. Phys. 1976, 47, 4086-4089. [CrossRef]

46. Chen, Z.; Li, W.; Li, R.; Zhang, Y.; Xu, G.; Cheng, H. Fabrication of highly transparent and conductive indium-tin oxide thin films with a high figure of merit via solution processing. Langmuir 2013, 29, 13836-13842. [CrossRef] [PubMed]

47. Banerjee, P.; Lee, W.; Bae, K.; Lee, S.B.; Rubloff, G.W. Structural, electrical, and optical properties of atomic layer deposition Al-doped ZnO films. J. Appl. Phys. 2010, 108. [CrossRef]

48. Illiberi, A.; Scherpenborg, R.; Roozeboom, F.; Poodt, P. Atmospheric spatial atomic layer deposition of In-doped ZnO. ECS J. Solid State Sci. Technol. 2014, 3, P111-P114. [CrossRef]

49. Ye, Z.-Y.; Lu, H.-L.; Geng, Y.; Geng, Y.; Gu, Y.-Z.; Xie, Z.-Y.; Zhang, Y.; Sun, Q.-Q.; Ding, S.-J.; Zhang, D.V. Structural, electrical, and optical properties of Ti-doped $\mathrm{ZnO}$ films fabricated by atomic layer deposition. Nanoscale Res. Lett. 2013, 8, 1-6. [CrossRef] [PubMed]

50. Burstein, E. Anomalous optical absorption limit in InSb. Phys. Review 1954, 93, 632-633. [CrossRef]

51. Morkoç, H.; Özgür, Ü. Zinc Oxide: Fundamentals, Materials and Device Technology; Wiley-VCH: Weinheim, Germany, 2009.

52. Pisarkiewicz, T.; Zakrzewska, K.; Leja, E. Scattering of charge carriers in transparent and conducting thin oxide films with a non-parabolic conduction band. Thin Solid Film. 1989, 174, 217-223. [CrossRef]

53. Jain, A.; Sagar, P.; Mehra, R.M. Band gap widening and narrowing in moderately and heavily doped $n$ - $\mathrm{ZnO}$ films. Solid State Electron. 2006, 50, 1420-1424. [CrossRef]

54. Kim, W.M.; Kim, J.S.; Jeong, J.; Park, J.; Baik, Y.; Seong, T. Analysis of optical band-gap shift in impurity doped $\mathrm{ZnO}$ thin films by using nonparabolic conduction band parameters. Thin Solid Film. 2013, 531, 430-435. [CrossRef]

(C) 2015 by the authors; licensee MDPI, Basel, Switzerland. This article is an open access article distributed under the terms and conditions of the Creative Commons by Attribution (CC-BY) license (http:/ / creativecommons.org/licenses/by/4.0/). 